УДК 796.322.2: 004

DOI https://doi.org/10.26661/2663-5925-2021-2-15

\title{
ОСОБЛИВОСТІ КІБЕРСПОРТИВНОГО НАПРЯМУ РОЗВИТКУ ГОЛОВНОЇ ЛІГИ ФУТБОЛУ (MLS)
}

\author{
Хіменес Х. P. \\ кандидат наук з фізичного виховання $і$ спорту, \\ доцент кафедри теорії спорту та фізичної культури \\ Львівський державний університет фізичної культури \\ імені Івана Боберського \\ вул. Костюшка, 11, Львів, Украӥна \\ orcid.org/0000-0002-8677-6701 \\ kh.khimenes@gmail.com
}

Ключові слова: фізична культура, учні, ліцеей, боротьба, зміст, варіативність.
Професійний спорт розвивається з урахуванням умов і запитів, які продукує сучасний світ (потреба в розвагах у часи складної пандемії 3 усіма обмеженнями, які вона зумовлює тощо). Фактично кожна із професійних ліг ігрових видів спорту сьогодні як інструмент підвищення зацікавленості аудиторії застосовує все нові розробки суспільства, зокрема найновіші комп'ютерні й інформаційні технології. Отже, маємо нині велику кількість нових видовищних продуктів, зокрема на кіберспортивній арені. У цю тенденцію потрапляє і головна ліга футболу (MLS), яка сьогодні також має, що представити своєму глядачеві. Мета - виявити особливості побудови системи кіберспортивних змагань iз футболу на прикладі MLS. Результати. Провідними змаганнями 3 футболу на кіберспортивній платформі, зокрема тими, які розвиваються під егідою MLS, сьогодні є кількаетапний Кубок eMLS, який проводиться iз 2018 року (Серія 1, Серія 2, Кубок eMLS). Щороку формат його проведення вдосконалюється, а також розширюється кількість командучасниць, що представляють окремі клуби самої MLS та кількість глядачів таких матчів. Із 2020 року популярності набуває і так званий eMLS Tournament Special, який також нині пропонує цікаву та насичену змагальну діяльність у межах віртуальної ігрової діяльності з футболу. MLS активно співпрацює з компаніями, що розробляють відеоігри (Play Station), з тими, які бажають бути спонсорами такого видовища (CocaCola, JLab, Pringles), а також із компаніями, які висвітлюють кіберігри для широкого загалу (Twitter, Twitch, Fox). Висновки. Кіберспортивний футбол щороку набуває все більшої популярності. Розроблені MLS формати змагань у режимі онлайн залучають усе більше учасників та фанів як на Північноамериканському континенті, так і в усьому світі. Такий спосіб проведення спортивних змагань загалом і футбольних зокрема дозволяє обійти велику кількість обмежень, пов'язаних із переїздами (що характерно для реальних стартів), а отже, суттєво спрощує можливість пересічних людей бути частиною спортивного видовища. 


\title{
FEATURES OF CYBER SPORTS DIRECTION MAIN FOOTBALL LEAGUE (MLS)
}

\author{
Khimenes Kh. R. \\ Ph. D., \\ Associate Professor at the Department of Theory of Sport and Physical Culture \\ Lviv State University of Physical Culture named after Ivan Boberskyj \\ Kostushko str., 11, Lviv, Ukraine, \\ orcid.org/0000-0002-8677-6701 \\ kh.khimenes@gmail.com
}

Key words: physical culture, students, lyceum, wrestling, content, variability.
Professional sports are developing, taking into account the conditions and, accordingly, the demands of the modern world (the need for entertainment in times of severe pandemic with all the restrictions it causes, etc.). In fact, each of the professional leagues of game sports today uses all new developments of society, including new computer and information technologies, as a mean for increase the interest of the audience. Thus, today we have a large number of new entertainment products, particularly in the esports arena. This trend also includes the major football league (MLS), which today also has something to present to its spectators. Purpose - to identify the features of creation a system of esports football competitions on the example of MLS. Results. The leading football competitions on the esports platform, in particular those that are being developed under the auspices of MLS today, are the multi-stage eMLS Cup, which has been held since 2018 (Series 1, Series 2, eMLS Cup). Every year the format of its holding is improved, as well as the number of participating teams representing individual clubs of MLS and the number of spectators of such matches is expanding. Since 2020, the so-called eMLS Tournament Special is gaining popularity, which also today offers interesting and intense competitive activities within the virtual football game. MLS actively cooperates with companies that develop video games (Play Station), with companies which want to sponsor such spectacle (Coca-Cola, JLab, Pringles), as well as with companies that cover cyber games to the masses (Twitter, Twitch, Fox). Conclusions. Esports football is becoming more and more popular every year. Online competition formats developed by the MLS are gaining more and more participants and fans on the North American continent and around the world. This way of sports competitions in general and football competitions in particular allows to bypass a large number of restrictions associated with moving (which is typical for real starts), and thus greatly simplifies the possibility people being a part of a sports spectacle.
Вступ. Технологічний прогрес суспільства нині розкриває нові можливості для розвитку різних сфер його існування (економіка, господарство, освіта тощо). Спортивна сфера, поза сумнівом, також черпає досягнення цього прогресу на власну користь. Найбільшою мірою в цьому зацікавлені саме професійні спортивні ліги, оскільки ключовим прагненням для них є збільшення прибутків.

Сучасні комп'ютерні й інформаційні технології дозволяють, зокрема, цим організаціям реалізовувати новітні спортивні технологічні завдання на кіберспортивній платформі.

У більшості професійних спортивних ліг нині існує власна система кіберспортивних змагань, яка щороку вдосконалюється 3 урахуванням суспільних запитів. Варто відзначити, що проведення таких турнірів приносить лігам значні фінансові поповнення, які також мають тенденцію до зростання.

Упровадження розробок професійних спортивних ліг у віртуальний простір нині відбувається в різних напрямах. Окремі з них (NBA, NFL, FIFA/ UEFA, FIBA/ULEB) акцентують увагу на впровадженні та постійному вдосконаленні відеоігор і систем змагань, що побудовані на них, інші (NHL, MLB, ATP, PGA) більш активно освоюють віртуальне середовище для перенесення туди свого реального продукту [1].

Умови реального проведення матчів нині ускладнені внаслідок пандемії, яка охопила світ, тому переведення ігрової діяльності в режим онлайн деякою мірою дозволяє організаціям професійного спорту утримати свого глядача. Цікавим $є$ те, що упродовж останніх двох років авдиторія фанів 
професійних видів спорту дещо омолодилася. Так, iRacing на Fox відзначає, що середній вік глядачів змагань NASCAR у режимі онлайн зменшився на 3 роки, NBA наводить дані, за якими $48 \%$ глядачів NBA 2k20 були віком до 45 років [1;3].

Нещодавно і головна ліга футболу (Major League Soccer, MLS) почала активно працювати на кіберспортивній платформі. Нині в цієї організації вже $\epsilon$ власна сформована і досить прибуткова кіберспортивна підструктура eMLS, яка займається проведенням кіберспортивних турнірів із футболу.

Зважаючи на тенденції розвитку сфери професійного спорту й умови, які диктує сучасне суспільство, доцільно з'ясувати особливості кіберспортивного напряму розвитку професійного спорту загалом та футболу (на прикладі MLS) зокрема.

Мета - виявити особливості побудови системи кіберспортивних змагань із футболу на прикладі MLS.

Матеріал та методи дослідження. Дослідження публікацій науково-популярного та публіцистичного характеру, матеріалів офіційного сайту головної ліги футболу (MLS). Для реалізації визначеної мети нами використовувалися такі методи досліджень: аналіз і узагальнення даних; теоретична інтерпретація та пояснення; аналіз документальних матеріалів.

Виклад основного матеріалу дослідження. Major League Soccer - фактично остання організація професійного спорту, яка застосувала віртуальний формат проведення своїх ігор. У 2018 р. вперше був проведений Кубок еMLS. Ці кіберспортивні змагання проводяться спільно MLS та франшизою EA Sports FIFA. Даний турнір служить офіційним кваліфікатором Ліги спершу на EA Sports FIFA Global Series, а потім і на Кубок світу FIFA eWorld. Проводяться ці кіберзмагання на платформі Play Station.

У зазначеному році Кубок еMLS проводився під час ігрового фестивалю PAX East у Бостоні. У турнірі взяли участь 19 команд, які були розподілені на Східну і Західну конференції. У команді кіберспортсмена було по три гравці, двоє з яких представляли один клуб MLS. У регулярному сезоні сформовані команди грали одна 3 одною двічі за коловою схемою в межах власних конференцій. Вісім кращих (по 43 кожної Конференціï) переходили в наступний тур так званого нокауту. Згідно із запропонованим форматом, два фіналісти проходили на участь у Кубку світу FIFA eWorld 2018, а призовий фонд змагань становив $\$ 10$ 000, які отримував переможець змагань [7].

Офіційним партнером та спонсором eMLS у проведенні матчів такого формату стала компанія "Coca-Cola".

Дещо відрізнявся формат проведення змагань eMLS у 2019 р. Так, їх було розподілено на три етапи: Серія 1, Серія 2 та сам Кубок eMLS. Варто зазначити, що кількість учасників цього сезону зросла до 22 (Східна конференція - 12, Західна - 10). Отже, система змагань 2019 р. складалася вже із трьох кваліфікаційних раундів - раунду "First-round bye" (Cеріï 1 та 2), у якому було визначено по двоє переможців із кожної конференції, які одразу потрапляли до півфіналу раунду нокаутів у межах плей-оф (складався із чвертьфінального, півфінального та фінального етапів), не брали участь у першому його етапі, шляхом нарахування бонусних балів; раунду нокаутів (“Knockout phase") у межах регулярного чемпіонату (3 команди від конференції, які проходили до першого етапу нокаутів плей-оф), раунду «Останній шанс» ("Last chance bracket”), де команди отримували останню можливість потрапити до восьми кращих від своєї конференції (по 1 команді від конференції) [11].

Система змагань в eMLS побудована таким чином, що кращі команди конференцій змагаються лише у фінальному матчі плей-оф, що аналогічно схемі проведення реальних футбольних матчів MLS. Переможці Серій 1 та 2 в цьому сезоні отримали по \$ 5000 призових. Призові для чемпіона Кубку eMLS становили у 2019 р. вже \$ 15000.

2020 р. для Кубку eMLS знаменувався зростанням кількості учасників вже до 25 і внесенням коректив до формату проведення змагань. Так, у Серіях 1 та 2 визначалися кращі учасники, яким нараховувалися бали (відповідно по 6, 3 та 1 балу для 1-ого, 2-ого та 3-ого місць у межах конференцій). До чвертьфіналу етапу нокаутів виходили по двоє кращих від конференції. До етапу вильоту (перший етап плей-оф iз 2020 р.) потрапляли учасники, що в серійних змаганнях посіли з 5 по 11 місця. Учасники, що посіли 12-у та 13-у позиції, проходили далі у чвертьфінал етапу «Останній шанс» (раунд 2), усі інші - у раунд 1 етапу «Останній шанс». Переможці Серій 1 та 2 отримували по \$ 7500. Розподіл призового фонду Кубку еMLS у 2020 р. відбувся за такою схемою: \$12 500 отримав чемпіон, \$ 5000 - учасник, який посів 2-е місце, ще $\$ 1250$ отримав гравець, що посів 3-є місце [4].

Представництво у футбольному Кубку eMLS 2021 зросло до 27 команд. Формат змагань порівняно з попереднім сезоном не зазнав вагомих змін, лише зросла відповідно кількість команд у конференціях та збільшилася кількість днів для кожних змагань (з одного до двох) [6]. Водночас зріс і призовий фонд для даних змагань. Так, у серійних змаганнях учасники з першого по третє місце отримали винагороду в розмірі $\$ 7500, \$ 3750$ та \$ 1875 відповідно, а призовий фонд у Кубку, за який боролися 11 учасників, зріс порівняно 3 попереднім роком до $\$ 35000$, які розподілили 
в підсумку так: \$20000 отримав переможець, \$ 10000 - команда, яка посіла друге місце, ще $\$ 5000$ - команда на третій позиції [5]. Окрім того, три кращі учасники зможуть взяти участь одразу у плей-оф EA SPORTS FIFA 21 Global Series Північної Америки [5].

3 організаційних моментів віртуального сезону 2021 р. варто відзначити, що eMLS залучила до партнерства компанію "JLab", яка стала офіційним аудіо та мікрофонним партнером Ліги. Відтепер учасники змагань користуються навушниками JLab Play та використовують мікрофони Talk Cheez-It. A Pringles повертаються як офіційний закусочний партнер eMLS. Також eMLS продовжує свою співпрацю з компанією "Coca-Cola" як офіційним партнером своїх ігор.

Окрім ігор професійних геймерів, проводяться матчі такого ж формату і серед фанів американського соккеру в міжсезоння ігор MLS (eMLS Fan Challenge), що підтримує захоплення цим видом спорту. Кожні двоє із трьох опитаних фанів MLS зазначають, що регулярно грають у комп'ютерний футбол, а понад 75\% опитаних уважають, що наявність такої можливості має вагоме значення для розвитку соккеру загалом.

У 2021 р. упродовж двох днів трансляції еMLS League Series 2 було зафіксовано 45000 тисяч одночасних переглядів ігор глядачами, що було відзначено як новий рекорд Ліги і 24\% приріст порівняно з аналогічним показником 2020 р. [2].

Спеціально для підвищення рівня зацікавленості глядачів eMLS створила профілі eMLS Player у співпраці з компанією "Pringles" для висвітлення унікальних історій гравців еMLS. Ці історії транслюються на каналах, що належать ы експлуатуються еMLS.

Зростання кількості кіберспортивних футбольних команд, отже, ы призового фонду, а також збыльшення глядацької авдиторії таких ігор із року в рік засвідчують високий рівень популярності віртуального футболу, що спричиняє появу нових форматів змагань, окрім кубкових. Так, у 2020 р. Ліга MLS започаткувала турнір, у якому взяли участь професійні гравці та гравці кіберспорту FIFA 20 Global Series від EA Sports.

Турнір дістав назву "eMLS Tournament Special" і проводиться за підтримки Coca-Cola i Play Station упродовж п'яти тижнів. За цей час 16 команд змагаються на вихідних (по 4 гри щотижня). В останній тиждень відбуваються фінальні ігри. Цікавим $\epsilon$ те, що ігри відбуваються способом прямого вибування. Команда, що програла, залишає змагання. Транслюються такі матчі партнерами ліги Fox Sports 1 та Fox Deportes [10].

Команди MLS, які беруь участь в eMLS Tournament Special, формуються 3 одного професійного гравця Ліги та так званого eMLS pro (геймер). Кожна гра відбувається віддалено, учасники змагаються 3 різних місць. Гравці MLS грають у Першій лізі, а гравці eMLS змагаються один 3 одним - у Другій лізі. Перемагає команда, яка має кращий сумарний бал [8-9].

Під час пандеміï Fox Sports багаторазово проводив трансляції кіберспортивних змагань. Ця компанія взяла на себе трансляцію eNASCAR iRacing Pro Invitational Series ra World of Outlaws, a нещодавно почала подібну співпрацю із MLS у цьому напрямі. Усі ці дії спрямовані на підтримку зацікавленості глядачів у складних умовах, які в багатьох аспектах забороняють безпосередній людський контакт [9].

Сезон 2021 p. eMLS складався вже із трьох турнірів, що транслювалися у прямому ефірі. Кожен iз цих турнірів проходив протягом двох днів, подвоївши кількість годин, витрачених на змагання eMLS у сезоні 2020 p.

У 2021 р. чемпіон змагань отримав \$ 40000 призових. Спостерігається і суттєве зростання кількості глядачів від першого до другого сезону. Тобто такі ігри є цікавими та, вочевидь, приноситимуть дохід у MLS [2].

У підсумку варто зазначити суттєвий прогрес у розвиткові кіберспортивного напряму MLS. Однак Ліга веде досить приховану фінансову діяльність, а тому вказати на рівень доходу від даного джерела складно. Ми схильні вважати, що активізація такої діяльності, постійне зростання кількості учасників кіберспортивних змагань із футболу, глядачів, спонсорів, розширення співпраці $з$ телекомпаніями, які транслюють відеозмаганння, приносять значні фінансові ресурси до цієї організації.

Висновки. Система кіберспортивних змагань у Головній лізі футболу (MLS) побудована 3 урахуванням тенденцій розвитку технологічної сфери, економічних засад функціонування спорту на території Північної Америки та, що не менш важливо, запитів глядацької авдиторії.

Ключовими турнірами в межах цієї системи сьогодні $\epsilon$ Кубок eMLS, який проводиться iз 2018 р. і включає кілька етапів, кожен із яких передбачає високу грошову винагороду для переможців та призерів. Щороку вносяться корективи до формату його проведення, а також зростає кількість команд-учасниць, що представляють окремі клуби самої MLS, кількість глядачів таких матчів.

У 2020 р. був започаткований також eMLS Tournament Special, який також сьогодні пропонує цікаву та насичену змагальну діяльність на кіберспортивній платформі.

Загалом MLS активно співпрацюе 3 компаніями, що розробляють відеоігри (Play Station), 3 тими, які бажають бути спонсорами такого видо- 
вища (Coca-Cola, JLab, Pringles), а також 3 компаніями, які висвітлюють кіберігри на широкі маси (Twitter, Twitch, Fox). Це дозволяє активно розвивати зазначений напрям і отримувати вагомі прибутки від нього.
Перспективи подальших досліджень. На наступних етапах дослідження планується 3'ясувати особливості побудови кіберспортивних змагань та загалом віртуальної діяльності інших професійних ліг ігрових видів спорту.

\section{ЛIТЕРАТУРА}

1. Хіменес Х. Досягнення сучасних професійних ліг ігрових видів спорту у віртуальному середовищі. Молодь та олімпійський рух : матеріали XIV Міжнародної конференції молодих учених, 19-20 травня 2021 р., м. Київ.

2. eMLS Cup 2021 presented by Coca-Cola to kick off Saturday. Sporting Kansas City. URL: https://www. sportingkc.com/news/emls-cup-2021-presented-coca-cola-kick-saturday (дата звернення: 15.03.2021).

3. eMLS Innovates for Broadcast TV. TDR. URL: https://thedalesreport.com/esports/emls-innovationfor-broadcast-tv/ (дата звернення: 29.06.2021).

4. eMLS League / 2020 Season / eMLS Cup. URL: https://fifa-esports.fandom.com/wiki/EMLS_League/ 2020 Season/eMLS Cup.

5. eML $\bar{S}$ League / $20 \overline{1}$ Season / eMLS Cup. URL: https://fifa-esports.fandom.com/wiki/EMLS_League/ 2021 Season/eMLS Cup.

6. Major League Soccer and Electronic Arts locked in the competitive schedule and new online format for the 2021 season of eMLS. Cynopsis Media. URL: https:/www.cynopsis.com/12-17-20-emls-kicks-off-21plans/ (дата звернення: 17.12.2020).

7. Major League Soccer announces details for first eMLS Cup tournament. URL: https:/www.mlssoccer.com/ news/major-league-soccer-announces-details-first-emls-cup-tournament (дата звернення: 21.02.2018).

8. MLS, eMLS players join forces in FIFA 20 for eMLS Tournament Special presented by CocaCola and Playstation. MLSsoccer. URL: https://www.mlssoccer.com/news/mls-emls-players-join-forces-fifa-20emls-tournament-special (дата звернення: 14.04.2020).

9. Nicholson J. MLS and FOX to host eMLS Tournament Special. Esports Insider. 2020. URL: https://www.esportsinsider.com/2020/04/emls-tournament-special/ (дата звернення: 14.04.2020).

10. Pursell Ch. FOX Sports Lines Up eMLS Tournament Special. Esports business summit. 2020. URL: https:/www.esportsbiz.com/fox-sports-lines-up-emls-tournament-special/ (дата звернення: 13.04.2020).

11. What you need to know for 2019 eMLS Cup at PAX East in Boston on March 30. URL: https://www.mlssoccer. com/news/details-revealed-2019-emls-cup-pax-east-boston-march-30 (дата звернення: 26.03.2019).

\section{REFERENCES}

1. Khimenes Kh.R. Dosyagnennya suchasnykh profesiynykh lig igrovykh vydiv sportu u virtualnomu seredovyshchi [Achievements of modern professional leagues of game sports in the virtual environment]. Materialy XIV Mizhnarodnoyi konferentsiyi molodykh vchenykh "Molod ta olimpiyskyy rukh" (19-20 travnya 2021 r., Kyiv). [Ukrainian]

2. eMLS Cup 2021 presented by Coca-Cola to kick off Saturday. Sporting Kansas City. https://www.sportingkc.com/news/emls-cup-2021-presented-coca-cola-kick-saturday (2021, March, 15). [English]

3. eMLS Innovates for Broadcast TV. TDR. https://thedalesreport.com/esports/emls-innovation-for-broadcast-tv/ (2021, July, 29). [English]

4. eMLS League/2020 Season/eMLS Cup. https://fifa-esports.fandom.com/wiki/EMLS League/2020 Season/eMLS Cup.

5. eMLS Leagūe/2021 Season/eMLS Cup. https://fifa-esports.fandom.com/wiki/EMLS_League/2021_ Season/eMLS Cup [English]

6. Major League Soccer and Electronic Arts locked in the competitive schedule and new online format for the 2021 season of eMLS. Cynopsis Media. https://www.cynopsis.com/12-17-20-emls-kicks-off-21-plans/ (2020, December, 17). [English]

7. Major League Soccer announces details for first eMLS Cup tournament. https://www.mlssoccer.com/ news/major-league-soccer-announces-details-first-emls-cup-tournament (2018, February, 21). [English]

8. MLS, eMLS players join forces in FIFA 20 for eMLS Tournament Special presented by Coca-Cola and Playstation. MLS soccer staff. https://www.mlssoccer.com/news/mls-emls-players-join-forces-fifa-20emls-tournament-special (2020, April, 14). [English]

9. Nicholson J. (2020). MLS and FOX to host eMLS Tournament Special. Esports Insider https://www.esportsinsider.com/2020/04/emls-tournament-special/ (2020, April, 14). [English]

10. Pursell Ch. (2020). FOX Sports Lines Up eMLS Tournament Special. Esports business summit. https://www.esportsbiz.com/fox-sports-lines-up-emls-tournament-special/ (2020, April, 13). [English]

11. What you need to know for 2019 eMLS Cup at PAX East in Boston on March 30. https://www.mlssoccer. com/news/details-revealed-2019-emls-cup-pax-east-boston-march-30 (2019, March, 26). [English] 